Theme 5: Partnership Approaches

\title{
The undergraduate research project as co-creation: can we describe new forms of learning gain?
}

\author{
Julie Wintrup, University of Southampton \\ Why is the undergraduate research project an important focus for
learning?
}

Whilst extra-curricular engagement projects and international exchanges offer invaluable opportunities to individuals, not all students are able to participate. In health disciplines, widening-access trends are not reflected in higher levels of participation in more privileged activities, some of which are associated with preexisting social and economic capital (Bridger, 2015). Student representation activities similarly require a high level of commitment, often beyond the scope of those who commute, are in paid work or have caring responsibilities (Healey et al, 2014). Learning regimes, assessment for academic credit and processes leading to the award of a qualification, in contrast, shape all students' encounters with education and are quality-assured. Yet students only rarely contribute meaningfully to course or curriculum design (the overarching purpose and philosophy, pedagogic methods, assessment approaches and modes of learning) which are determined typically by academics and, in health programmes, external agents such as regulatory bodies.

The final-year project offers one such opportunity to influence one's own learning. It remains universally valued (Healey and Jenkins, 2009) and impressive examples of research-driven education proliferate (Watkins, 2014). However, the burden of governance requirements and their associated administration has significantly reduced the use of empirical methods by health students, who are often encouraged to pursue evidence-based practice (EBP) approaches - valued, as Ryan (2016) discusses, but locating students, as White (2016) determines, as users, not creators, of knowledge. Professional education is often characterised by what Ainley (2010:1) calls 'this pressure for certification', with its focus on competences, work-based learning and assessment, high levels of taught/contact hours and inflexibility.

Innovative research approaches offer health students a unique opportunity to direct their own learning in such intellectually and practically-stretching ways as: generating and evaluating research questions; planning and directing project work while evaluating their strengths and resources; collaborating with peers, practice colleagues, patients and carers, and with supervisors; and, importantly, engaging with ethics review processes and principles.

\section{Undergraduate research and its relationship to notions of learning gain}

Being honest about the problems and difficult choices that face society, while remaining committed to improving the lives of others, means that health professionals inhabit a complex, uncomfortable intellectual space. Health practices, often by necessity, simplify the complicated and deny the harsh realities of others' lives, for the sake of order, efficiency and survival. Research, by its nature, does the opposite. Exploration of the minutiae of lives or organisations or policies is necessary - from multiple and often conflicting perspectives. Questioning, speculating and learning from other disciplines, exploring different worldviews in order to analyse and theorise, are taken for granted as essential to health research. I suggest each is equally essential to health practice, if we want to move beyond asking 'What works?' and to question why things work in the way they do. Schleicher (2015: 10) wants such a stance to define 'learning gain', challenging higher education to find ways to 
assess and reward such things as:

"..ways of thinking, involving creativity, critical thinking, problem-solving and decision-making; ways of working, including communication and collaboration; tools for working, including the capacity to recognise and exploit the potential of new technologies; and the social and emotional skills that help people live and work together"

Health is not alone in needing to move on from describing higher education's benefits, or students' learning gain, as decontextualised lists of skills measured in piecemeal ways.

\section{Co-creating: a new form of learning gain?}

Undergraduates' research interests are likely to differ from those of academics in important ways. Their questions may be generated within networks and interest groups, by the experiences of being a novice or working directly with patients and carers or simply because of generational, cultural or personal concerns. Studentgenerated research questions disrupt taken-for-granted ideas of control and expertise, and offer one starting point of many towards the co-creation of new knowledge. Yet it remains the case that, even when rich, social, process-driven learning takes place, it is likely to be assessed by a single, individually-scripted piece of writing - the thesis or report - against a generic and prescribed set of learning outcomes. We bemoan the strategic learner, rationally calculating the swiftest and least risky route to a high grade, whilst our assessments are often designed to engender such a stance.

Academics open to disruption and participatory research relationships - such central concepts in healthcare research - are well placed to grasp the nettle of developing trustworthy methods of assessing students' progress, over time, in the forms of personal change that Schleicher (2015) describes. Fairness and transparency, in processes interpreted and applied by assessors able to exercise self-awareness, evaluative ability and skilful judgement, are of course central to high-quality assessment. Conflicts brought to the surface by describing learning gain as cocreation of knowledge - such as student-as-consumer approaches (Molesworth et al, 2009), resources available to academics and students, or pressures to certify predetermined outcomes (Ainley, 2010) - ought to be welcomed, as a prompt for analysis and debate and as a reminder that students' careers, as part of a shifting global workforce, will be very different from our own.

If health education's purpose is, then, ultimately driven by the needs of society and of healthcare, with all its complexities, contingencies and its pressing need for innovation and renewal, who better to equip for the challenges ahead than our undergraduates?

\section{Reference list}

Ainley, P. (2010) 'To the dissertation and beyond: Independent study in the new undergraduate curriculum.' Compass: The Journal of Learning and Teaching at the University of Greenwich, 1(2).

Bridger, K. (2015) Academic perspectives on the outcomes of outward student mobility. International Unit / HEA. Available at:

https://www.heacademy.ac.uk/sites/default/files/resources/Academic\%20perspective 
s\%20on\%20the\%20outcomes\%20of\%20outward\%20student $\% 20$ mobility\%20\%20Final\%20Report.pdf (Accessed: 1 April 2017).

Healey, M., Flint, A. and Harrington, K. (2014) Engagement through partnership: students as partners in learning and teaching in higher education. York: Higher Education Academy. Available at:

https://www.heacademy.ac.uk/sites/default/files/resources/Engagement through par tnership.pdf (Accessed: 1 April 2017).

Healey, M. and Jenkins, A. (2009) Developing Undergraduate Research and Inquiry. York: Higher Education Academy.

Molesworth, M., Nixon, E. and Scullion, R. (2009) 'Having, being and higher education: the marketisation of the university and the transformation of the student into consumer.' Teaching in Higher Education, 14(3).

Ryan, E.J. (2016), 'Undergraduate nursing students' attitudes and use of research and evidence-based practice - an integrative literature review.' Journal of Clinical Nursing, 25(11-12).

Schleicher, A. (2015) Value-Added: How do you measure whether universities are delivering for their students? HEPI 2015 Annual Lecture. Available at:

http://www.hepi.ac.uk/wp-content/uploads/2016/01/Andreas-Schleicher-lecture1.pdf (Accessed: 1 April 2017).

White, L. (2016) 'That girl's got guts: relationships and everyday life for women with irritable bowel syndrome (IBS).' Reinvention: an International Journal of Undergraduate Research, 9(2) Available at:

http://www2.warwick.ac.uk/fac/cross fac/iat//reinvention/issues/volume9issue2/white (Accessed: 17 June 2017). 